\title{
A influência do Fairtrade no desenvolvimento do capital social: o caso dos cafeicultores da Cooperativa "Dos Costas"
}

\author{
The influence of Fair-tradein the Development of Capital: the Dos \\ Costas Coffee Cooperative case \\ Bruno Henrique Aguiar ${ }^{1}$, Marcelo Márcio Romaniello ${ }^{1}$, Djalma Ferreira Pelegrini² (D)

\begin{abstract}
1 Programa de Pós-graduação em Desenvolvimento Sustentável e Extensão, Departamento de Administração e Economia, Universidade Federal de Lavras (UFLA), Lavras (MG), Brasil. E-mails: brunobaratiaguiar@gmail.com; mromaniello@ufla.br ${ }^{2}$ Empresa de Pesquisa Agropecuária de Minas Gerais (EPAMIG), Uberaba (MG), Brasil. E-mail: djalma@epamig.br
\end{abstract}

\begin{abstract}
Como citar: Aguiar, B. H., Romaniello, M. M., \& Pelegrini, D. F. (2022). A influência do Fairtrade no desenvolvimento do capital social: o caso dos cafeicultores da Cooperativa "Dos Costas", 60(2), e224545. https://doi.org/10.1590/18069479.2021 .224545
\end{abstract}

\begin{abstract}
Resumo: Este trabalho é fruto do interesse em compreender a influência do Fairtrade no desenvolvimento do capital social. Para tanto, o estudo teve como principal objetivo investigar a influência do Fairtrade no desenvolvimento do capital social entre os cafeicultores Fairtrade associados à Cooperativa "Dos Costas", que tem sede no município de Boa Esperança-MG. A condução da pesquisa permitiu investigar a existência de relações de confiança, cooperação e participação entre os atores, bem como os laços que mantêm o grupo unido e caminhando na mesma direção. A pesquisa qualitativa contou com a realização de análise documental, entrevistas em profundidade intencional (3 cafeicultores gestores da cooperativa) e por conveniência (6 cafeicultores associados), e com a observação não participante. Os resultados evidenciaram a influência do Fairtrade no fomento ao trabalho colaborativo, fortalecendo as já existentes relações de confiança, cooperação e participação entre os cafeicultores, e contribuindo ainda para a formação de novos laços e o desenvolvimento do capital social.
\end{abstract}

Palavras-chave: capital social, desenvolvimento local, cafeicultura Fairtrade.

\begin{abstract}
This work is the result of an interest in understanding the influence of Fair-trade in the development of capital. In addition, the study aimed at investigating the influence of Fair-trade on the development of capital among Fair-trade coffee growers associated with the Cooperative "Dos Costas", which is based in the municipality of Boa Esperança-MG. The conduct of the research allowed the investigation of the existence of relationships of trust, cooperation and participation between the actors, as well as the ties that hold the group together and moving in the same direction. The qualitative research included documentary analysis, intentional in-depth interviews (three coffee farmers who manage the cooperative) and for convenience (six associated coffee farmers), and non-participant observation. The results showed the influence of Fair-trade in fostering collaborative work, strengthening the already existing relationships of trust, cooperation and participation, among coffee growers, and also contributing to the formation of new ties and the development of capital.
\end{abstract}

Keywords: social capital, local development, Fair Trade coffee crops.

\section{Introdução}

Este trabalho é fruto do interesse em compreender a influência do Fairtrade na formação e no desenvolvimento do capital social. De início aceitou-se como princípio que o segmento da cafeicultura pode ser estudado a partir de sua organização social, e que pode ser avaliado a partir do grau de união dos cafeicultores no formato de associações e cooperativas. No seio de tais organizações são estabelecidas relações de confiança e cooperação entre os atores. Ao tratarmos da organização social em torno da cafeicultura Fairtrade, nosso interesse dirige-se 
para as relações sociais estabelecidas entre os cafeicultores, com vistas à construção de um projeto coletivo baseado na confiança, cooperação e participação.

O Fairtrade busca organizar uma lógica alternativa entre produtores, consumidores e agentes de mercado; logo, seus principais objetivos são: oferecer espaços diferenciados de mercado para produtores desfavorecidos pela dinâmica mercadológica e, ao mesmo tempo, estimular a solidariedade entre membros por meio da autogestão. Diálogo, transparência e respeito são pilares de uma parceria comercial que busca maior equidade nas relações comerciais (Fairtrade International, 2018; Mascarenhas, 2007; Pedini, 2011).

Para que um grupo de produtores (associação ou cooperativa) se torne parte do movimento do comércio justo e obtenha o selo de certificação Fairtrade, tais produtores devem seguir normas e parâmetros estabelecidos pela Fairtrade International (FLO) e observarem princípios como a participação dos agricultores nas decisões da organização, o respeito a normas ambientais e trabalhistas e a orientação para o desenvolvimento social.

A filosofia Fairtrade incentiva o associativismo local, principalmente entre os agricultores familiares. Não sem motivos, uma das exigências para a adesão ao movimento do comércio justo é estar associado a um grupo de agricultores que comungue desse mesmo objetivo. Assim, ao construírem relações de confiança, cooperação e participação nas decisões do grupo, os atores se tornariam mais próximos de serem protagonistas de seu próprio desenvolvimento.

O Brasil possui, atualmente, 42 organizações de pequenos produtores (Opps), e Minas Gerais é o estado que concentra a maior parte das organizações de pequenos produtores (Opps) que atuam na cafeicultura Fairtrade. Poço Fundo, Varginha, Santana da Vargem, São Gonçalo do Sapucaí, Poços de Caldas, Andradas, Paraguaçu, Carmo de Minas, Manhaçu, Lajinha, Nova Resende, Petúnia e Boa Esperança são os municípios onde se situam as organizações de pequenos produtores que contam com o diferencial da certificação Fairtrade. Em especial, situada no município de Boa Esperança, sul de Minas Gerais, encontra-se a Cooperativa dos Produtores de Café Especial de Boa Esperança Ltda. "Dos Costas" (Coordenadora Latino-americana e do Caribe de Pequenos Produtores e Trabalhadores do Comércio Justo, 2018).

O grupo, composto por 49 cafeicultores, constituiu em 2005 a Associação Comunitária “Dos Costas", com o objetivo de trabalhar em prol dos pequenos produtores, buscando alternativas econômicas e sociais que apoiassem a permanência dos pequenos cafeicultores na atividade rural. A identidade, com o nome de Associação Comunitária "Dos Costas", se deu em referência a um bairro rural de Boa Esperança-MG, denominado "Dos Costas", endereço de muitos dos seus associados.

A Associação Comunitária "Dos Costas" foi constituída com o objetivo de criar oportunidades aos pequenos cafeicultores de Boa Esperança, no contexto em que ocorreu a expansão da cafeicultura praticada em grande escala em nível regional, a partir da implantação de extensas lavouras e mecanização intensiva. O grupo de cafeicultores associados percebeu que somente poderia permanecer na atividade mediante a busca de alternativas em conjunto, a partir da adoção de estratégias capazes de possibilitar melhor inserção nos mercados, praticar compras compartilhadas e alternativas de financiamento, em face da competitividade da cafeicultura de grande escala.

O grupo cresceu e no ano de 2008, com 69 cafeicultores, a Associação Comunitária "Dos Costas" se juntou ao Fairtrade; já em 2009 constituíram a Cooperativa dos Produtores de Café Especial de Boa Esperança Ltda., carinhosamente chamada por seus membros de Cooperativa "Dos Costas". Em 2018, o quadro de cafeicultores associados era de 149 cafeicultores, todos com atividades produtivas na região de Boa Esperança, Minas Gerais. Esses cafeicultores perceberam a oportunidade de inserção da organização nesse mercado alternativo como 
possibilidade de fortalecimento da agricultura familiar, mediante a melhoria de sua renda e participação nas decisões do grupo.

No presente estudo lançou-se o olhar sobre o grupo de cafeicultores organizados na Cooperativa "Dos Costas". O objetivo deste artigo é então investigar a influência do Fairtrade no desenvolvimento do capital social (confiança, cooperação e participação) entre os cafeicultores Fairtrade associados à Cooperativa "Dos Costas".

De nosso ponto de vista, o desafio consistiu em encontrar evidências de que, de fato, a filosofia Fairtrade promoveu incremento de capital social na comunidade de cafeicultores do município de Boa Esperança. Ou, dito de outra maneira: considerando o desenvolvimento local da comunidade, como avaliar o efeito da filosofia Fairtrade sobre o desenvolvimento do capital social, na forma de confiança, cooperação e participação?

Além desta primeira parte introdutória, a seção seguinte trata do Fairtrade enquanto movimento e mercado. O esforço de avaliar a influência do Fairtrade sobre o capital social e sobre o processo de desenvolvimento social da comunidade dos cafeicultores vinculados à Cooperativa "Dos Costas", requer também um aprofundamento teórico acerca de duas noções que entendemos fundamentais, a saber: capital social e desenvolvimento local.

A terceira seção aborda as metodologias de pesquisa empregadas na pesquisa, seguida da apresentação, discussão dos resultados e considerações finais.

\section{Referencial teórico}

Tratando das temáticas do associativismo e do cooperativismo, alguns especialistas e pesquisadores desenvolveram terminologias próprias, na tentativa de expressar os graus variados de cooperação, participação e confiança das comunidades em conceitos mais "pungentes".

Putnam (1997), ao estudar por anos as diferenças regionais entre o norte e o sul da Itália, encontrou no trabalho colaborativo dos cidadãos forte ligação entre os níveis de desenvolvimento econômico e social dessas regiões. Porém, é notório que tanto a abordagem do capital social (Coleman, 1990; Putnam, 1997) como as vertentes que tratam da teoria da reciprocidade (Sabourin, 2011, dentre outros), como também a perspectiva crítica desenvolvida por Neves (2003), que atribui as deficiências do sistema associativo rural ao intervencionismo estatal (que fomenta a geração de lideranças personalistas), deixam clara a posição de que se pode relacionar as características próprias dos grupos sociais (traduzidas pelo grau de cooperação, participação e confiança que manifestam) ao desenvolvimento de ações conjuntas, capazes de desencadear processos de desenvolvimento social, econômico e tecnológico.

Essa reflexão reforça o argumento de que a construção de um projeto coletivo por parte dos associados é de fundamental importância para a existência e o fortalecimento dessas organizações. Logo, solidariedade, mobilização, engajamento e confiança são essenciais para que o grupo possa se organizar, suportando suas adversidades e solucionando seus próprios problemas (Neves, 2003; Sabourin, 2011).

Há, contudo, outra questão que merece ser discutida e diz respeito ao fato de que não se pode negar a origem exógena do movimento Fairtrade, e que tende a mascarar o discernimento a respeito da influência do Fairtrade no grau de organização social da comunidade. Além disso, as próprias noções que tomamos como referenciais (reciprocidade, capital social, dentre outras) foram elaboradas para interpretar sociedades e contextos muito distantes de nosso objeto de estudo, e por essa razão podem não ser perfeitamente adequadas para investigar o problema de pesquisa que temos diante de nós.

A nosso ver, a afirmação de Neves (2003), segundo a qual, no Brasil, grande parte das associações de agricultores tem vida curta e está fadada ao descrédito por parte dos associados, 
não invalida as teorias da reciprocidade e do capital social, porém que, para o nosso caso, tais teorias detêm menor poder explicativo.

\subsection{Fairtrade, movimento e mercado alternativo}

O comércio justo é um movimento socioeconômico internacional que usa as relações comerciais para promover padrões produtivos de consumo e comercialização, pautados por princípios éticos e responsáveis, a fim de contribuir para o desenvolvimento dos produtores e de suas comunidades. O mecanismo de certificação Fairtrade é dotado de princípios e critérios que têm por objetivo assegurar que toda a cadeia (produção, comercialização e consumo) observe os princípios e normas relacionados com a preservação ambiental, igualdade social e melhor distribuição de renda e riqueza (Fairtrade International, 2014; Flocert, 2018).

O movimento Fairtrade surgiu a partir de iniciativas de ajuda humanitária dos países do hemisfério Norte aos povos do hemisfério Sul, na busca de relações mais justas entre empresas e consumidores dos países ricos para com os produtores dos países pobres. Dentre as principais diferenças da certificação Fairtrade com outros tipos de certificações, como Rainforest e UTZ, estão a exigência de um preço mínimo que deve ser adotado durante as transações comerciais e a especificidade do produtor certificado: agricultores organizados em cooperativas ou associações (Pedini, 2011).

Quando um grupo de produtores (associação ou cooperativa) inicia o processo para a obtenção da certificação Fairtrade, organização e produtores são apresentados a um conjunto de normas e critérios que modificam a estrutura organizacional da cooperativa (ou associação) e mesmo dos produtores. Os critérios e as normas da certificação, assim como o contato com essa nova estrutura comercial, passam a acompanhar e a influenciar as ações dos agricultores certificados (Fairtrade International, 2014; Flocert, 2018).

Por meio de gestão descentralizada, a Coordenadora Latino-americana e do Caribe de Pequenos Produtores e Trabalhadores de Comércio Justo (Clac) é a coproprietária da organização do sistema de Comércio Justo Internacional e atua em rede, representando todas as organizações Faitrade da América Latina e do Caribe certificadas e outras organizações de comércio justo. Atualmente, são mais de 700 organizações membros da Clac em 24 países do continente (Coordenadora Latino-americana e do Caribe de Pequenos Produtores e Trabalhadores do Comércio Justo, 2018).

A metodologia de gestão da Clac incentiva a criação de coordenadorias nacionais, que em conjunto com a coordenadoria latino-americana têm o papel de representar e promover os interesses, o empoderamento e o desenvolvimento de seus membros (produtores) e de suas comunidades.

No Brasil, a coordenadora responsável por essa representação das organizações de produtores é a Associação das Organizações Fairtrade do Brasil (Brfair). A Brfair conta, atualmente, com 23 organizações de pequenos produtores (Opps) associadas e tem a intenção de alcançar e representar todas essas Opps brasileiras.

A base atual do movimento Fairtrade, além de estimular o comércio entre produtores do hemisfério Sul e consumidores do hemisfério Norte, incentiva relações comerciais entre produtores e consumidores nos países do hemisfério Sul (Sul - Sul) e hemisfério Norte (Norte - Norte), em nível local e nacional nos países do Sul e do Norte.

O preço mínimo se resume a um preço pré-fixado, calculado com base nos custos de produção mundiais, que garante aos produtores receitas um pouco maiores que seus custos de produção. Assim, os produtores Fairtrade, vinculados às suas cooperativas ou associações, podem vender 
seus produtos por melhores preços, e ainda contam com um bônus, ou seja, um prêmio social acima do valor de mercado para garantir melhorias nas condições de vida dos produtores.

Com o propósito de uma comercialização justa, o movimento Fairtrade atua no mercado à medida que busca reduzir as desigualdades econômicas do comércio de commodities agrícolas, em benefício de produtores oriundos de países do hemisfério Sul (prioritariamente) e com baixos níveis de renda.

Os produtos certificados e com selo Fairtrade sinalizam a adoção de critérios sociais, econômicos e ambientais em seu processo produtivo aos consumidores que os observam e os seguem. De acordo com Mascarenhas (2007), esses produtos e processos oriundos do Fairtrade devem incorporar princípios dispostos nas convenções culturais da humanidade, como os princípios da Organização Internacional do Trabalho (OIT), a Carta dos Direitos Humanos e, posteriormente, as dimensões do desenvolvimento sustentável. A International Fairtrade Labelling Organisation (FLO), criada em abril de 1997, a partir da união de várias organizações de comércio justo, passou a determinar as diretrizes de certificação para o Fairtrade em todo o mundo, determinando os critérios necessários para enquadramento de grupos de produtores, empresas e importadores participantes do movimento (Fairtrade International, 2018). Esses critérios e princípios procuram emancipar os produtores marginalizados e suas organizações, além de buscar maior igualdade no comércio internacional, e devem ser seguidos por todas as organizações ligadas ao movimento Fairtrade, como afirma Mascarenhas (2007, p. 6).

\begin{abstract}
Na parceria com as organizações de produtores o movimento pretende: desenvolver uma parceria comercial; praticar o respeito mútuo preservando culturas; transparência e accountability, dar informações para acesso a mercados; ter uma comunicação aberta e construtiva; facilitar o diálogo e arbitragem na resolução dos conflitos; melhorar as condições comerciais; pagar um preço justo; financiar a colheita e promover relações comerciais de longo prazo. Na área de direitos humanos: assegurar direitos de trabalhadores e produtores; possibilitar uma remuneração justa e boas condições de trabalho; cumprir leis nacionais e manter os direitos humanos de acordo com a ONU; assegurar que os padrões de trabalho da OIT sejam cumpridos; proibir o trabalho forçado; promover o direito de organização e negociação coletivas; remunerar de forma igualitária o trabalho de homens e mulheres; evitar, no acesso ao trabalho, discriminação de raça, cor, sexo, religião, política; proibição do trabalho infantil. Promover o desenvolvimento sustentável das organizações de produtores: fortalecer as organizações de pequenos produtores, bem como o direito de participação nas decisões de produtores e trabalhadores; financiar a capacitação e o desenvolvimento de recursos humanos, especialmente mulheres; encorajar ativamente melhores práticas ambientais e métodos responsáveis de produção.
\end{abstract}

É importante ressaltar que o comércio justo atua no mercado e não é seu objetivo superar o capitalismo, todavia atua contraditoriamente às práticas capitalistas, garantindo preços mínimos e "justos", cobrindo custos sociais e ambientais; e ainda oferecendo pré-financiamentos e estabilidade de preços no longo prazo (Laforga, 2005).

\title{
2.20 capital social
}

Existe consenso que o sociólogo James Coleman teria inserido o debate sobre o capital social no meio acadêmico. Segundo Coleman (1990), o capital social refere-se a um componente do capital humano que permite a um determinado grupo ou sociedade cooperar na formação de novos grupos e associações. Desse modo, certas ações comuns aos atores de uma estrutura seriam facilitadas pela ação coletiva e seus resultados.

Assumindo a credibilidade de Coleman, Monastério (2006) afirma que foram os trabalhos de Putnam que tiveram o maior destaque. Putnam (1997) aprofundou o debate a respeito do papel da participação cívica na dinâmica democrática, estabelecendo relações de causa e efeito entre a comunidade cívica e o desempenho institucional da Itália moderna. Nessa direção, concebeu comunidade cívica como a comunidade que cumpre quesitos como participação 
cívica, igualdade política, solidariedade, confiança, tolerância e práticas associativas, para então apresentar o capital social referindo-se aos aspectos das organizações sociais que permitem a ação e a cooperação para benefício mútuo e solução de problemas da ação coletiva, quais sejam as redes, as normas e a confiança (Monastério, 2006).

A virtude cívica, entendida neste trabalho como pertencimento social e participação dos cidadãos nas decisões do local, constitui a base fundamental para um grupo ou comunidade trabalhar em prol de interesses em comum. Putnam (1997) ressalta que quando há falta de virtude cívica os cidadãos buscam interesses próprios e particulares. O civismo explicaria por que algumas comunidades estavam mais aptas que outras para gerir a vida coletiva e manter suas instituições eficazes. Nelas vai sendo construído um rico tecido social, em que a capacidade de auto-organização, por meio de vínculos solidários, colaboração horizontal, canais de participação, instituições e organizações, estimula a confiança e a reciprocidade nos relacionamentos entre grupos e atores sociais. Enfim, o capital social resulta em cidadãos empoderados, capazes de tomar decisões coerentes sobre seu próprio futuro (Jara, 2001).

Serafim et al. (2007) e Silva \& Cândido (2009) afirmam que não existe uma definição única e objetiva a respeito do capital social, entretanto há consenso sobre sua importância como fator influente nas diversas sociedades locais, pela convergência de fatores como cooperação e ajuda mútua.

Partindo da perspectiva de Putnam (1997), Marteleto \& Silva (2004) concordam que as relações existentes entre os indivíduos representados por sujeitos sociais (indivíduos, grupos, organizações etc.) e conectados por algum tipo de relação fazem parte do capital existente nas sociedades. Essas relações, que correspondem ao capital social, servem de base para o desenvolvimento social e econômico.

Na teoria da "força dos laços fracos", Mark Granovetter (1973) argumenta que laços casuais, com pouco investimento emocional, constituem os laços fracos, que seriam responsáveis pela construção de pontes entre os "sujeitos sociais". Já os laços fortes são existentes entre amigos próximos "ligados ao ego" e teriam pouca influência, pois agregam pouco valor na busca por recursos (Carvalho, 2014). Nota-se que em regiões, comunidades e mesmo em organizações os laços fracos têm papel fundamental no direcionamento da rede, não excluindo os laços fortes, pois estes estão presentes e têm seu papel, inclusive na confiança entre os atores.

Durston (2003) faz distinção entre capital social individual e capital social comunitário, sugerindo que o capital social individual se manifesta nas relações entre duas pessoas por meio de redes egocêntricas; ou seja, quando os laços de proximidade, como família e amigos, regem o tipo de capital. De outra forma, o capital social comunitário é entendido como plenamente coletivo; ou seja, está presente nas estruturas de cooperação comunitária bem como no sistema sociocultural de cada comunidade e em suas estruturas normativas, gestionárias e sancionadoras.

Dallabrida (2006) avança nessa conceituação quando afirma que o capital social comunitário fortalece a participação comunitário-associativa, complementa os serviços públicos e interfere positivamente no associativismo empresarial. Por essa visão, o desenvolvimento de uma determinada sociedade, localizada temporal e espacialmente, demanda elevada densidade de capital social.

Dentre os conceitos fundamentais na definição do modelo de desenvolvimento de uma dada região destacam-se a confiança, a cooperação, a participação social, o aprendizado e o compartilhamento de recursos entre os atores envolvidos, conforme compreendem Vale et al.(2006).

A confiança representa um componente indispensável à existência do capital social. Assim, quanto maior a confiança, maior é a probabilidade de existência de solidariedade (ajuda mútua 
entre os atores) e participação social nas decisões que dizem respeito ao grupo. Desse modo, a confiança interpessoal e a participação nas instituições sociais e políticas são as principais facilitadoras de ações coletivas em torno de metas comuns (Fukuyama 1996; Baquero, 2000).

A confiança interpessoal possibilita ações colaborativas, uma vez que os sujeitos partilham de valores comuns, e à medida que se relacionam sabem com quem "podem contar" ou não. Putnam (1997) afirma que quando não existe confiança os indivíduos preferem agir isoladamente. Tabosa et al. (2004) afirmam que a confiança é a essência do capital social e sem ela é impossível existir cooperação.

A confiança solidifica a cooperação; cooperação é definida por Coleman (1990) como a capacidade dos indivíduos de trabalhar por um bem comum. Apoiado em Coleman, Putnam (1997, p. 117) afirma que "através da confiança são formadas as cadeias de reciprocidade e os indivíduos assumem deveres em retribuir favores recebidos".

Para Romaniello (2009), o fortalecimento das relações de confiança potencializa as relações de cooperação, desencadeando componentes participativos. O autor destaca que a confiança alimenta a previsibilidade das relações sociais e gera cooperação entre as pessoas. Já a cooperação alimenta a confiança e a reciprocidade entre os membros do grupo e incrementa a participação social.

É fato que não existe definição única e objetiva a respeito do capital social, entretanto há um consenso sobre sua importância e influência no desenvolvimento de sociedades locais e na convergência de fatores como confiança e cooperação. Assim, o capital social é capaz de proporcionar a coordenação de esforços coletivos rumo à obtenção de objetivos em comum, ou mesmo benefícios coletivos (Serafim et al., 2007; Silva \& Cândido, 2009).

Tais benefícios coletivos são considerados por Olson (1999) como "benefícios indivisíveis", ou seja, aqueles que uma vez consumidos por um grupo não podem ser negados a uma pessoa desse grupo, mesmo que este não tenha se dedicado à sua obtenção. Assim, a decisão do indivíduo sobre se irá ou não contribuir para a obtenção do benefício coletivo depende da soma dos custos da ação. O indivíduo tomará a decisão de participar caso os benefícios sejam superiores aos custos. O fato é que o engajamento desses indivíduos em contribuir para obtenção de benefícios coletivos está diretamente ligado à existência e ao estoque de capital social em determinado grupo (Olson, 1999).

Contudo é importante compreender que o simples fato de existirem grupos de indivíduos que têm em particular uma atividade, ou que se identifiquem enquanto agricultores, trabalhadores ou operários, não configura a existência ou estoque de capital social. Tratando especificamente de associações e cooperativas, Neves (2003) aponta a construção de um projeto coletivo como fundamental para o funcionamento, fortalecimento e sobrevivência dessas organizações, de modo que atributos como solidariedade, cooperação voluntária e criação de soluções para problemas precisos sejam inerentes aos atores, bem como à organização.

Putnam (1997) e Fukuyama (1996) concordam que o capital social é um ativo presente em muitos processos de desenvolvimento territorial e local. A união colaborativa e organizada decorrente do ativo de capital social é certamente fator indispensável à prosperidade econômica e à boa governança.

O capital social possibilita que certos indivíduos direcionem seus esforços para o trabalho coletivo, no sentido de cooperação entre os atores locais. Pode-se inferir que quanto mais elevado for o capital social maior será a cooperação de ações que resultem em oportunidades de crescimento, melhorias, mudanças e intervenções na sociedade na qual os indivíduos estão inseridos, propiciando o desenvolvimento local (Abramovay, 1999). 
Se o capital social concerne na capacidade de organização dos atores que conservam vínculos solidários, colaboração horizontal, canais de participação, instituições e organizações que estimulam a confiança e a reciprocidade nos relacionamentos entre grupos e atores sociais, presume-se que esse capital social pode promover benefícios coletivos que contribuem para o desenvolvimento local (Romaniello, 2009).

\subsection{Desenvolvimento local}

Com frequência ocorrem muitas discussões e confusões no domínio das ciências sociais com respeito às noções de desenvolvimento e crescimento, que ora se completam ora se opõem. Porém, como são termos distintos devem ser tratados com cautela. Há autores que concebem crescimento e desenvolvimento "econômico" como processos semelhantes e outros que defendem uma visão ampliada a respeito dessa diferenciação (Dallabrida, 2010). Em vista disso, aceitamos a proposta de tratar o desenvolvimento como um processo sociocultural, que pode se caracterizar como um processo econômico, perene e contínuo, influenciado tanto por agentes externos quanto pelos próprios atores e comunidade (Ávila, 2006).

Registrado em pequenas unidades territoriais, esse processo pode ser capaz de promover o dinamismo econômico e a melhoria da qualidade de vida da população e representar uma transformação na base econômica e na organização social local, por meio das potencialidades e capacidades da população local. Assim, para ser local, o "desenvolvimento" deve elevar as oportunidades sociais, a viabilidade e competitividade da economia local, promover aumento de renda e das formas de riqueza, ao mesmo tempo em que assegura a conservação dos recursos naturais (Buarque, 1999).

Apesar de seu forte conteúdo interno, o processo de desenvolvimento local está inserido em uma realidade mais ampla e complexa. Buarque (1999) esclarece que esse processo interage e recebe influências e pressões positivas e negativas. Entretanto, mesmo quando decisões externas (de ordem política ou econômica) oferecem influência direta na reestruturação socioeconômica do município ou da localidade, o desenvolvimento local requer a contínua mobilização dos atores locais em torno de um projeto coletivo. Para tanto, concorrem os capitais humano (conhecimentos, potencialidades e capacidades da população local) e social (confiança, cooperação e participação).

Goulart (2006) reporta a existência de uma gama de estudos que investigam arranjos, redes e o impacto econômico de atividades específicas em casos de sucesso e de fracasso. Entretanto, pouco se tem discutido a respeito das transformações no espaço territorial que se desenrolam em fenômenos sociais, o que justifica a condução de estudos sobre capital social e desenvolvimento local.

A discussão sobre desenvolvimento local centra-se, primeiramente, entre o agente do desenvolvimento, entendido como a própria comunidade ou grupo em questão. Oliveira (2001) aponta que não basta que as pessoas encontrem satisfação em um conjunto de requisitos e no bem-estar social; é necessário incluir a questão da cidadania no debate sobre o desenvolvimento local. Assim compreendida, a cidadania corresponde a um estado de espírito. É através da cidadania que os cidadãos lutam pela qualidade de vida, enquanto o sujeito não é mais particular, e sim coletivo, o que inclui a garantia de seus direitos civis, políticos, sociais e mesmo ambientais. Essa capacidade de participação da cidadania nas decisões locais é uma dimensão substantiva do desenvolvimento local (Oliveira, 2001).

Romaniello (2009) considera que o verdadeiro controle efetivo da "coisa pública" é reflexo de uma cidadania organizada, compreensão que reforça o debate sobre o capital social coletivo. Assim, a descentralização das responsabilidades tem sentido, considerando-se que o poder 
é atribuído à base da administração, à sociedade organizada em organizações da sociedade civil, tais como associações, cooperativas, organizações da sociedade civil de interesse público (Oscips) e organizações não governamentais. Em resumo: o desenvolvimento local ocorre a partir de ações coletivas conduzidas pela sociedade civil organizada.

\section{Metodologia}

No presente tópico apresentamos detalhes acerca da estrutura da pesquisa e dos procedimentos metodológicos empregados, tendo em vista o cumprimento dos objetivos propostos.

O estudo exploratório investigou a história e a evolução dos cafeicultores Fairtrade associados à Cooperativa "Dos Costas", sua realidade e a influência do Fairtrade no desenvolvimento do capital social (confiança, cooperação e participação) entre os cafeicultores.

A pesquisa foi realizada entre 27 de junho de 2018 e 4 de fevereiro de 2019. Em 2018, o quadro de cafeicultores associados era de 149 cafeicultores, todos com atividades produtivas na região de Boa Esperança, Minas Gerais.

A metodologia qualitativa se mostrou adequada para a investigação proposta. Alencar \& Gomes (1998), Demo (2008) e Martins (2004) afirmam que as metodologias qualitativas privilegiam a análise de microprocessos, através das ações sociais individuais e grupais, permitindo um estudo em amplitude e profundidade. Com a adoção dessa metodologia pretendeu-se garantir a diversidade de olhares sobre os atores sociais que desempenharam diferentes ações, o que tornou possível a coleta e análise dos dados e uma melhor aproximação com a realidade social implícita.

Foram empregadas diferentes técnicas como forma de auferir dados e interpretar respostas oriundas das relações sociais entre os atores durante o estudo de caso. Para o estudo, foram adotadas as seguintes técnicas de pesquisa:

- análise documental;

- entrevista intencional em profundidade (com roteiro semiestruturado);

- entrevista por conveniência em profundidade (com roteiro semiestruturado);

- observação não participante.

Em razão do entrelaçamento entre análise documental, entrevista intencional em profundidade, entrevista por conveniência em profundidade e observação não participante, como técnicas investigativas, foi possível realizar uma triangulação sistemática de perspectivas (Flick, 2009).

A análise documental foi realizada a partir da investigação do acervo de documentos cedidos pela cooperativa (relatórios, atas, cartilhas, cartas, textos, livros, imagens e vídeos) como forma de aproximar os pesquisadores da realidade dos pesquisados, através de suas memórias arquivadas entre os anos de existência da organização. Gil (2008) destaca que a pesquisa documental aproxima o passado do presente, possibilita a investigação de processos de mudança social e cultural e é de grande valia para a pesquisa social.

Foram realizadas entrevistas por conveniência na primeira etapa da entrevista em profundidade. Para Gil (2008), nesse método os indivíduos são escolhidos pela acessibilidade ou por serem mais fáceis de serem avaliados. Para tanto, os pesquisadores participaram de uma das reuniões mensais organizadas pelo departamento agronômico da cooperativa.

Durante a reunião realizada no dia 24 de setembro de 2018, tratou-se de temas relacionados à produção e produtividade, transição para a agricultura orgânica, comercialização dos cafés produzidos, apoio da organização aos cafeicultores associados e auditoria na produção orgânica. Ao final da reunião, seis cafeicultores foram entrevistados.

Seguindo a entrevista em profundidade, foram realizadas entrevistas intencionais com o presidente, a diretora administrativa e o diretor financeiro da Cooperativa "Dos Costas". 
Necessário registrar que o corpo diretor da cooperativa é composto por cafeicultores associados à cooperativa. Realizadas no dia 23 de agosto de 2018, as entrevistas abordaram temas relacionados ao trabalho coletivo e à organização do grupo enquanto cooperativa. Segundo Flick (2009), o método intencional é útil quando se procura obter informações-chave, fornecidas apenas por atores que ocupam posições estratégicas em organizações ou grupos específicos.

A necessidade de aprofundamento nos temas específicos da pesquisa foi atendida a partir do emprego de roteiros de entrevista (intencionais e por conveniência), o que de outra forma não seria possível.

Já a observação não participante foi realizada durante a participação dos pesquisadores na reunião de 24 de setembro de 2018, e durante a atuação de um dos pesquisadores como secretário executivo da Associação das Organizações de Produtores Fairtrade do Brasil (Brfair), instituição que trabalha para representar as organizações de pequenos produtores certificadas pelo comércio justo no país. A adoção desse procedimento permitiu que os pesquisadores construíssem uma visão holística sobre o tema investigado. Ao atuar como secretário executivo da Brfair desde junho de 2018, o pesquisador pôde ver e vivenciar o dia a dia dos cafeicultores e da cooperativa. Durante a observação não participante foram elaboradas notas de campo para posterior sistematização das informações coletadas, em acordo com a sugestão de Gil (2008), para quem esse método é apropriado para o estudo de condutas manifestas na vida social.

O principal desafio deste estudo foi investigar a influência do Fairtrade no desenvolvimento do capital social entre os cafeicultores Fairtrade associados à Cooperativa "Dos Costas", e encontrar uma possível relação de contribuição do ativo (capital social) ao atual estágio de desenvolvimento do grupo. Para tanto o estudo analisou as relações de confiança, cooperação e participação como fatores fundamentais ao processo de desenvolvimento investigado.

A análise das informações obtidas mediante a realização das entrevistas em profundidade, intencionais e por conveniência, envolveu a audição exaustiva das gravações, organização das informações em relatos, transcrições e leitura minuciosa desses documentos, comparação das informações, além da identificação do que existe ou não em comum entre elas. Após a extração das comparações, dimensões e conceitos, foi realizada a organização dos conceitos e dados em categorias de análise.

As informações coletadas por meio da análise documental e da observação não participante permitiram maior aproximação entre os pesquisadores e a realidade investigada. O rico conteúdo dos documentos estudados, a realização das entrevistas intencionais e por conveniência e a observação não participante ofereceram aporte para a análise e discussão dos resultados da pesquisa.

\section{Resultados e discussão}

As diferenças regionais e a pluralidade de estágios de desenvolvimento sempre despertaram olhares e questionamentos entre estudiosos de diferentes campos de estudo. Assim, pesquisadores têm buscado responder a seguinte pergunta: quais seriam as estratégias e caminhos que levaram um grupo ou uma comunidade ao seu atual estágio de desenvolvimento? É verdade que não existem receitas e fórmulas para a promoção do desenvolvimento, entretanto existem caminhos e medidas que o incentivam e promovem.

\subsection{Cooperativa "Dos Costas"}

Fundada em 2009 por 69 cafeicultores, a Cooperativa "Dos Costas" é fruto do trabalho colaborativo que teve início em 2005 com a Associação Comunitária "Dos Costas". No intervalo de nove anos a evolução do grupo enquanto cooperativa apresentou resultados importantes. 
Atualmente, a Cooperativa "Dos Costas" exporta a maior parte da produção de seus cooperados, realizando exportações diretas. Os cafés certificados Fairtrade são vendidos para compradores que atuam nesse mercado específico, e o valor agregado pela comercialização dos cafés Fairtrade produzidos na região de Boa Esperança-MG tem retornado a esses cafeicultores, estimulando a economia local.

A união dos cafeicultores na Cooperativa "Dos Costas" estimulou a cooperação e ofereceu benefícios econômicos e oportunidades de comercialização. Juntos, os cafeicultores possuem maior poder de barganha frente ao mercado externo. Por meio da cooperativa, os cafeicultores têm acesso ao mercado nacional de cafés industrializados. Segundo o Conselho dos Exportadores de Café do Brasil (2019), o consumo interno brasileiro foi de 20,5 milhões de sacas em 2017.

Outro grande passo dado pelo grupo foi o início do trabalho com orgânicos. A produção orgânica é incentivada como alternativa de mercado, redução do uso de agrotóxicos e obtenção de melhores preços pagos aos produtores. O interesse em fornecer um produto diferenciado tem permitido que os produtores aprendam novas técnicas de manejo, diminuindo a histórica dependência por insumos químicos externos, que antes eram considerados indispensáveis à produção cafeeira.

A maioria dos agricultores tem começado a trabalhar com orgânicos por confiar na seriedade e suporte da organização. Esse suporte está relacionado com a assistência técnica de qualidade, com visitas periódicas às propriedades, ao apoio e incentivo financeiro durante o período de transição para a produção orgânica (tendo em vista a dificuldade em iniciar a cafeicultura orgânica) e ao apoio na comercialização da produção.

O grupo se mostra preocupado com a conservação ambiental e tem trabalhado em diferentes âmbitos. Como parte das exigências da certificação Fairtrade, a organização de produtores deve investir no "prêmio Fairtrade" parte do valor recebido pelo produto certificado em benefícios de impacto social.

O chamado prêmio pago pelo produto certificado Fairtrade é um valor fixo que deve ser pago separadamente do valor de compra do produto. Por exemplo, em vendas internacionais, se o café é vendido por USD $\$ 1,35$ por libra peso, o comprador deve pagar além dos USD \$1,35 o valor de USD\$ 0,20 por libra peso referente ao valor do prêmio. Assim, se uma cooperativa recebe USD \$ 57.143,66 pela venda de 320 sacas de café, a mesma cooperativa recebe USD\$ $8.467,57$ referentes ao prêmio pago pelo café certificado Fairtrade, que devem ser devolvidos aos cooperados e à comunidade, revertidos em projetos de impacto socioambiental e melhoria de qualidade da produção (Coordenadora Latino-americana e do Caribe de Pequenos Produtores e Trabalhadores do Comércio Justo, 2016).

O prêmio Fairtrade pago à Cooperativa "Dos Costas" financia projetos de melhoria da qualidade do café produzido, preservação e renovação de vegetação em áreas com nascentes, reflorestamento de áreas degradadas, erradicação de fossas negras, doação de mudas nativas e frutíferas e cuidados com o solo.

Um empreendimento que merece destaque é a iniciativa da "Cafeteria Xícara da Silva", que se tornou um ponto de encontro nas tardes da cidade, onde são servidos os cafés especiais produzidos por cafeicultores associados à cooperativa. A Cooperativa "Dos Costas" incentiva e valoriza o trabalho feminino; o nome da cafeteria é uma homenagem a todas as mulheres ligadas à cooperativa. A cooperativa promove a ministração de cursos de capacitação em culinária (doces, bolos, tortas e geleias) para as associadas, cujos produtos podem ser comercializados na cafeteria da organização.

A cooperativa ainda comercializa o café dos associados (torrado e moído) em seis diferentes versões, que podem ser adquiridos na Cafeteria Xícara da Silva, no site da cooperativa, como também em outros municípios. 
Os entrevistados (presidente, diretores e associados) tiveram grande interesse em relatar as ações desenvolvidas por iniciativa da cooperativa em favor da conservação ambiental na comunidade. A responsabilidade ambiental foi percebida nas respostas dos associados e pode ser creditada aos estímulos da certificação Fairtrade. Quando perguntada a respeito das melhorias no que concerne à conservação ambiental, a diretora administrativa afirmou que esse é um dos grandes ganhos do trabalho da cooperativa.

\begin{abstract}
Gostamos de citar dois casos de atos simples, mas exemplares: 1 . Um produtor relatou que não sabia mais chupar bala na rua porque não sabia o que fazer com a embalagem, pois não há lixos pela cidade. Acabo pondo tudo dentro do bolso para pôr no lixo em casa. 2. Se não fosse essa tal de "Fertreis" isso aqui teria virado um mar de plástico. Saindo do anedótico, podemos dizer que foi implantada uma consciência ambiental, que nos deixa satisfeitos pelos resultados práticos. (Entrevista realizada em 23 de agosto de 2018).
\end{abstract}

Como organização certificada, a cooperativa passa, anualmente, por uma auditoria realizada pela Flo Cert (certificadora responsável pela certificação Fairtrade). Durante o processo, o auditor responsável fiscaliza o cumprimento de uma série de requisitos relacionados a questões ambientais, sociais, econômicas e de gestão. O não cumprimento dos requisitos por parte da organização ou por parte dos produtores pode ser considerado uma não conformidade. As não conformidades recebidas podem levar o produtor, e até mesmo a organização, à exclusão da certificação Fairtrade (Cooperativa dos Produtores de Café Especial de Boa Esperança, 2018a).

Os requisitos dizem respeito ao cumprimento das normas trabalhistas e ambientais, rastreabilidade da produção, execução de projetos de preservação ambiental, preservação de nascentes, manutenção da coleta e reciclagem do lixo, redução do uso de agrotóxicos e trabalhos de preservação da saúde dos cafeicultores (Fairtrade International, 2014; Flocert, 2018). Os produtores e a Cooperativa “Dos Costas" têm cumprido com êxito os critérios exigidos pela certificação.

A lista de produtos perigosos utilizada pela Flo é um documento importante, que deve ser cumprida como requisito para a manutenção da certificação. São ao todo 353 produtos químicos que são divididos nas categorias: Lista Vermelha (Uso Proibido), Lista Laranja (Uso Restrito) e Lista Amarela (Lista Marcada). São 207 produtos descritos na lista vermelha que são proibidos pela certificação Fairtrade por serem altamente perigosos à saúde humana e ao meio ambiente; já os 39 produtos descritos na lista laranja só podem ser utilizados mediante prescrição técnica, com cautela, em situações extremas de infestações e doenças. Os produtos da lista laranja possuem um plano de erradicação de sua utilização pela Fairtrade Internacional; os 110 produtos descritos na lista amarela também só podem ser utilizados mediante prescrição técnica, com cautela, e são considerados perigosos pela Fairtrade Internacional (Cooperativa dos Produtores de Café Especial de Boa Esperança, 2018a).

Preocupada com a saúde e o bem-estar social de seus cooperados, a cooperativa desenvolve o projeto Saúde no Campo, que conta com a realização de visitas periódicas aos agricultores, oferecendo o suporte de uma enfermeira, e orientações a fim de que os cafeicultores e suas famílias dediquem maior atenção aos cuidados com sua saúde. O projeto atua na triagem das famílias, avaliação da segurança no trabalho e avaliação do saneamento básico rural (água e esgoto domésticos). Além disso, promove a realização de exames médicos como forma de auferir a existência de químicos nocivos à saúde no organismo desses produtores (Cooperativa dos Produtores de Café Especial de Boa Esperança, 2018a).

Durante as visitas de agrônomos e técnicos realiza-se a sondagem das condições laborais das máquinas e equipamentos agrícolas, enquanto eles orientam os cafeicultores a respeito dos perigos oferecidos pelos equipamentos e os reparos necessários para que o trabalho no campo seja realizado com segurança. 
Até o ano de 2016,98\% do esgoto doméstico rural eram destinados a fossas negras. Segundo a cooperativa, dentre 117 amostras de água colhidas, 82\% apresentaram pelo menos um tipo de contaminação (bactéria heterotrófica, coliformes totais, coliformes termorresistentes, Escherichia coli). A Cooperativa "Dos Costas" implantou 60 fossas sépticas (o equivalente a $25 \%$ do total de moradores rurais) no ano de 2017 e projeta que, até o final do ano de 2020, $100 \%$ das propriedades estejam com a água e o esgoto tratados por aparelho clorador de água e fossa séptica (Cooperativa dos Produtores de Café Especial de Boa Esperança, 2018b).

Expandindo a atuação da rede, cooperativa, cafeicultores e poder público contribuíram para que Boa Esperança fosse reconhecida oficialmente dentro do sistema Fairtrade, pelo Comitê Internacional de Cidades do Comércio Justo, como Cidade do Comércio Justo, desde setembro de 2017.

Para que esse reconhecimento fosse alcançado, a cooperativa tem trabalhado, desde 2015, junto às gestoras de fortalecimento da Coordenadora Latino-americana e do Caribe de Pequenos Produtores e Trabalhadores de Comércio Justo (Clac) e ao município, no cumprimento de critérios que levaram a esse reconhecimento.

Os critérios estabelecidos pelo Comitê Internacional de Cidades do Comércio Justo são: possuir uma declaração do município manifestando o interesse em fazer parte da campanha; possuir e incentivar o comércio de produtos Fairtrade no município; realizar eventos educativos sobre o comércio justo (com a comunidade); possuir um grupo de trabalho para promoção do Fairtrade em nível local e o consumo dos produtos Fairtrade em instituições públicas e privadas locais.

Os benefícios já elencados, somados ao histórico do trabalho colaborativo realizado pelo grupo de cafeicultores, oferece evidências sobre a existência de relações de confiança, cooperação e participação e suporte para a investigação proposta pelos pesquisadores.

\subsection{Confiança}

Componente fundamental à existência do capital social, a confiança solidifica as relações entre os atores que partilham objetivos em comum (Putnam, 1997; Romaniello, 2009). A confiança facilita e mesmo possibilita a cooperação e a participação dos atores sociais envolvidos, o que pode estar relacionado ao atual estágio de desenvolvimento do grupo estudado.

Assim, quanto maior a confiança maior é a existência de mecanismos de cooperação (ajuda mútua entre os atores) e participação nas decisões que dizem respeito ao grupo. Desse modo, a confiança interpessoal e a confiança nas instituições sociais e políticas são as principais facilitadoras de ações coletivas em torno de metas comuns, como afirma Baquero (2000).

A confiança entre os cafeicultores Fairtrade da região de Boa Esperança-MG foi avaliada tanto na observação das normas, condutas e valores compartilhados pelo grupo quanto na estrutura organizacional da cooperativa, que, através de uma gestão aberta e transparente, incentiva a confiança entre os cafeicultores e entre cafeicultores e instituição.

A organização se mostrou aberta ao diálogo e os cooperados têm total autonomia para participar das decisões relacionadas ao grupo. Foi evidenciado que a confiança entre os cafeicultores solidificou o capital social e proporcionou a sustentação de normas, condutas e valores que predispõem os cafeicultores para cooperar por meio da estrutura organizacional da cooperativa.

O relato do presidente da cooperativa apontou que esses cafeicultores são bastante unidos e confiam uns nos outros.

O grupo é bastante unido, tem sempre aqueles "mais ariscos", mas no geral os cafeicultores confiam uns nos outros e na organização. Por exemplo, quando há algum problema de caixa, os próprios produtores emprestam café ou dinheiro à organização. O Fairtrade estimulou esta confiança entre os membros, se não fosse a certificação Fairtrade, talvez o grupo não existiria atualmente. (Entrevista realizada em 23 de agosto de 2018). 
A afirmação do presidente reforça a existência de uma forte confiança entre cooperados e a organização. A prestação de contas referente ao ano de 2017 demonstra que a organização não passa por dificuldades financeiras. 0 "problema de caixa" referido está relacionado a uma ou outra venda efetuada com recebimentos futuros ou alocação de recursos para compra de equipamentos para a organização (exemplo: estrutura de torrefação própria). $O$ entrevistado esclareceu que os cooperados estão dispostos a ajudar e confiam na solidez da organização e em sua capacidade de honrar os compromissos assumidos.

Tais resultados confrontam a posição de Olson (1999), uma vez que sugerem que o comportamento dos indivíduos não é movido apenas por interesses econômicos. Os laços sociais constituídos durante a trajetória do grupo de cafeicultores reforçam a confiança e a dimensão do capital social existente. Nessa visão, os laços pessoais, as redes de relacionamento e a reciprocidade entre os cafeicultores podem explicar o processo de desenvolvimento local.

A gestão participativa estimulada pelo Fairtrade possibilitou a aproximação entre esses agricultores e a organização, criando e fortalecendo elos entre cafeicultores, e entre cafeicultores e a organização. A diretora administrativa apontou essa adesão como positiva para o fortalecimento dessa confiança.

A entrada da cooperativa e a adesão dos cafeicultores ao movimento do comércio justo fortaleceu os cafeicultores(as) enquanto grupo, porque como todos cresceram, eles verificaram a importância de pertencer a esse movimento. (Entrevista realizada em 23 de agosto de 2018).

A diretora administrativa destacou a obtenção de benefícios que ultrapassam a "porteira" e o individualismo. Contudo, é importante registrar que, como toda estrutura cooperativa, essa organização possui cooperados extremamente atuantes e cooperados que se interessam apenas pelas vantagens oferecidas pelos mecanismos de comercialização e facilidade de venda dos produtos.

Ser um cafeicultor Fairtrade e fazer parte do sistema Fairtrade pode ser considerado o principal benefício coletivo do grupo. O cafeicultor entrevistado $\mathrm{n}^{\circ} 1$ afirmou que mais de 100 cafeicultores aguardam a abertura da cooperativa para a entrada de novos associados. Durante a entrevista, sustentou a existência de sólida confiança entre cafeicultores e cooperativa, enquanto atestou sua experiência de vida enquanto diretor por um mandato de outra cooperativa com sede em Boa Esperança-MG.

Eu confio muito em meus companheiros "cafeicultores" e na atual gestão da cooperativa. Posso dizer que existe uma grande confiança entre os cafeicultores associados, e que a entrada para a certificação Fairtrade teve papel fundamental no fortalecimento dessa confiança. Falo com propriedade, pois fui diretor de uma grande cooperativa em Boa Esperança-MG, e fazendo uma comparação entre as duas organizações, os laços de confiança entre os cafeicultores associados e a Cooperativa "Dos Costas" são sólidos e estruturados, diferente da cooperativa na qual fui diretor. (Entrevista realizada em 24 de setembro de 2018).

Boa Esperança-MG é sede também de outra cooperativa de cafeicultores que segue a linha de atuação da maioria das cooperativas de cafeicultores brasileiros; gestão empresarial, unidades em outros municípios, venda de insumos e benefícios relacionados à assistência técnica, armazenamento e comercialização. O cafeicultor entrevistado $\mathrm{n}^{\circ} 1$ relatou que foi diretor dessa cooperativa "convencional" por um mandato, e que a ligação dos produtores com a organização fica centrada no simples armazenamento e na comercialização. Segundo ele, os laços de confiança, cooperação, bem como a participação dos cooperados nas decisões relacionadas ao grupo de cafeicultores Fairtrade, são fortes. Em sua visão, a adesão ao Fairtrade foi fundamental para esse fortalecimento. 
O cafeicultor entrevistado $n^{\circ} 2$ reforçou a confiança entre os cafeicultores, enquanto relatou sua experiência como diretor administrativo da Cooperativa “Dos Costas” por um mandato.

Estou com o grupo desde o início, quando éramos ainda uma associação. Temos uma boa confiança entre cafeicultores e organização; sou também um dos pioneiros na produção orgânica. Se não fosse o Fairtrade, acho que não chegaríamos ao que somos hoje. (Entrevista realizada em 24 de setembro de 2018).

Ficou evidente, pelas observações de campo e pelos relatos obtidos durante as entrevistas (a exemplo do relato do entrevistado $n^{\circ} 2$ ), que a confiança alcançada por esse grupo foi produto de longo prazo, que teve início na pré-formação da Associação Comunitária "Dos Costas" e prosseguiu no processo de construção dos princípios do associativismo, do compromisso coletivo e das interações extrafamiliares.

A adesão ao movimento Fairtrade representa um marco no processo de fortalecimento desse grupo de agricultores. A gestão democrática e participativa incentivou o comportamento associativo e o engajamento em ações coletivas, o que proporcionou melhor organização dos cafeicultores para solucionar os problemas comuns. Durante entrevista realizada no dia 24 de setembro de 2018, a cafeicultora entrevistada $n^{\circ} 6$ descreveu o comportamento cooperativo dos cafeicultores nos seguintes termos: "por ser uma cooperativa menor, somos uma família, a gente conversa, se ajuda e se entende. Digo que o Fairtrade nos ensinou a cooperar".

A confiança foi relatada por todos os entrevistados: confiança nos associados, confiança nos cafeicultores vizinhos, confiança no grupo em geral e confiança na cooperativa foram respostas que se cruzaram durante a aplicação dos questionários. A observação não participante permitiu ao pesquisador identificar a existência dessa confiança entre o grupo investigado.

O acesso de uma pessoa a um sistema associativo/cooperativo pode ser um mecanismo de inserção que o torna parte do processo de desenvolvimento local. Romaniello (2009) afirma que a capacidade de articulação e de influência dependerá, contudo, da forma como interage com os demais cooperados. Segundo ele, a interação, a confiança, a definição de objetivos comuns e a estruturação da rede social são questões fundamentais para compreender o processo cooperativista e a importância relativa do capital social para o desenvolvimento do local onde ocorre.

Foi possível concluir que a filosofia Fairtrade e a gestão participativa incentivada pelo sistema contribuíram para o fortalecimento da confiança, para a definição de metas e objetivos comuns, e ainda para a estruturação da rede social. O cooperativismo e os critérios exigidos pela certificação Fairtrade atuam como um indutor do trabalho colaborativo, que por sua vez fortalece a confiança entre cafeicultores e entre cafeicultores e organização. A realização da pesquisa permitiu reunir muitas evidências de que o cooperativismo e os princípios/critérios da certificação Fairtrade influenciaram o desenvolvimento do capital social entre os cafeicultores.

\subsection{Cooperação}

A ajuda mútua entre os atores, também definida como cooperação, é apresentada por Coleman (1990, p. 108) "como a capacidade dos indivíduos de trabalhar por um bem comum". A cooperação é capaz de proporcionar uma coordenação de esforços coletivos rumo à obtenção de objetivos em comum.

A cooperação baseada na confiança corrobora a argumentação de Romaniello (2009), quando afirma que confiança é um componente básico do capital social, pois promove a cooperação. Uma comunidade com alto nível de confiança está mais propensa a desenvolver o trabalho cooperativo; ao mesmo tempo, a própria cooperação gera confiança e, consequentemente, o 
desenvolvimento e a prosperidade econômica para a cafeicultura nas regiões com alto estoque de capital social.

Ficou evidente, mediante a observação não participante, que o trabalho colaborativo entre os cafeicultores rompe com as funções básicas da organização como armazenamento, comercialização e assistência técnica. O incentivo ao trabalho feminino e a comercialização dos alimentos produzidos pelas cooperadas na cafeteria demonstram a reciprocidade do trabalho coletivo e a valorização das cooperadas e cooperados. Confiança e cooperação são evidências do capital social entre os cafeicultores Fairtrade associados à Cooperativa "Dos Costas".

$O$ cafeicultor entrevistado $n^{\circ} 5$ relata que a organização e os cafeicultores procuram caminhar juntos, pois acreditam na reciprocidade e ajuda mútua entre os atores.

Quando um produtor tem um problema como a queda de produção devido à seca e fica descapitalizado, a cooperativa possui um fundo para ajudar esse produtor. A taxa de juros é baixa e o cafeicultor tem um apoio de até cinco anos para se recuperar financeiramente. (Entrevista realizada em 24 de setembro de 2018).

O apoio oferecido pela organização aos produtores que porventura venham a passar por adversidades climáticas e financeiras evidencia a cooperação recíproca que solidifica o capital social. A afirmação do cafeicultor entrevistado $n^{\circ} 5$ confirma a disposição de trabalhar em benefício do grupo, tanto por parte da cooperativa como dos cafeicultores.

Nota-se que quando os membros do grupo atuam em conjunto, seus integrantes valorizam o trabalho e as práticas são bem-sucedidas, o que cria laços de confiança e cooperação ao longo do tempo. Essa confiança pode permitir que o grupo dê passos audaciosos e se torne protagonista de sua própria história.

Os dados da pesquisa evidenciaram que a cooperação entre os cafeicultores Fairtrade está diretamente relacionada ao desenvolvimento do capital social, contribuindo também para construção de benefícios coletivos e melhoria da qualidade de vida e renda dos cafeicultores associados à cooperativa "Dos Costas".

\subsection{Participação}

Para Oliveira (2001), a participação social é uma dimensão substantiva do desenvolvimento local. Desse modo, a participação proporciona o engajamento dos cidadãos nas associações voluntárias e na vida cívica, potencializando a elevação do capital social e ainda ampliando benefícios sociais e materiais aos cafeicultores.

As entrevistas em profundidade (intencional e por conveniência) relataram a participação, através da presença ativa de parte desses cafeicultores nas Assembleias Gerais Ordinárias (anualmente, conforme exige o estatuto) e Assembleias Gerais Extraordinárias (mediante a necessidade da organização e dos cooperados); e através do contato entre os cafeicultores e a organização. Além da participação nas assembleias e reuniões de cooperados, diretoria e colaboradores trabalham para que a cooperativa seja também um espaço de diálogo, onde são apresentadas dúvidas, críticas e sugestões por parte dos cafeicultores associados, e em benefício do grupo.

Segundo Bordenave (1992), como nenhum homem é uma ilha, "fazer parte", "ter parte", "tomar parte", ou seja, participar é uma necessidade fundamental do ser humano. Entretanto, é importante destacar a diferença entre a participação passiva e ativa, o que difere o cidadão inerte do cidadão engajado. Uma participação social ativa é aquela em que os indivíduos tomam parte nas decisões, bem como na produção, gerência e usufruto dos bens da sociedade de maneira equitativa, como deve ser o caso do ambiente cooperativo. No dia a dia, durante 
consultas agronômicas, comercialização do café armazenado, busca dos materiais de colheita, consulta sobre a classificação dos cafés depositados, consultas sobre o estoque de cafés depositados, por exemplo, ocorre uma importante interação entre diretoria, colaboradores da cooperativa e cafeicultores, momento em que os cooperados apresentam reivindicações, críticas, sugestões, problemas e elogios.

A participação foi também evidenciada mediante a observação não participante. Os pesquisadores estiveram presentes em uma das reuniões de produtores, organizada pelo departamento agronômico da cooperativa. Durante a reunião, o grupo discutiu ativamente sobre questões relacionadas à produção e produtividade, transição para a agricultura orgânica, comercialização dos cafés produzidos, apoio da organização aos cafeicultores associados e auditoria na produção orgânica. Os cafeicultores se mostraram à vontade para expressar suas críticas, questionamentos, inquietudes, sugestões de melhoria e elogios.

A participação está relacionada à existência e intensidade do capital social, uma vez que, como principais indicadores da existência de capital social, confiança, cooperação e participação são fatores que contribuem para que o grupo caminhe unido em prol de benefícios coletivos (Romaniello, 2009).

A participação e a consciência política foram enfatizadas pelo presidente e pelos dois diretores entrevistados. A diretora administrativa explana essa consciência em sua fala sobre o senso de cidadania dos cafeicultores.

Nota-se a discussão sobre problemas relacionados à educação, saúde, estradas, lixo, política nacional, atividade do prefeito, secretariado, vereadores, nos pequenos grupos que se formam na cooperativa. Podemos informar que os cafeicultores participam das discussões na Prefeitura, na Câmara, no Fórum, ou nas regiões onde moram quando se trata de assuntos de interesse de suas comunidades. (Entrevista realizada em 23 de agosto de 2018 ).

Para Oliveira (2001), o debate sobre o desenvolvimento local está diretamente ligado à concepção de cidadania. Ao passo que o sujeito não é mais particular, e sim coletivo, o que inclui a garantia dos direitos civis, políticos, sociais e mesmo ambientais. Essa capacidade de participação cidadã nas decisões locais é uma dimensão substantiva do desenvolvimento local.

A virtude cívica definida por Putnam (1997), como pertencimento social e participação dos cidadãos nas decisões do local, é a base fundamental para um grupo ou comunidade trabalhar em prol de interesses em comum. Putnam (1997) ressalta que quando há falta de virtude cívica os "cidadãos buscam interesses próprios e particulares". Desse modo, o civismo explicaria por que algumas comunidades estavam mais aptas que outras para gerir a vida coletiva e manter suas instituições eficazes.

Os relatos apresentados durante as entrevistas apontam o envolvimento dos cafeicultores nas decisões relacionadas ao grupo e o reconhecimento de que um grupo participativo decide junto seu próprio caminho, como aponta o cafeicultor entrevistado $\mathrm{n}^{\circ} 3$.

Participa. Assembleia é pra isso, é a hora de ajudar a decidir o que será feito. Tem a assembleia para decidir sobre o uso do prêmio pago pelo Fairtrade, nessa decidimos o que retorna em benefícios a nós cafeicultores. (Entrevista realizada em 24 de setembro de 2018).

A assembleia para decidir sobre o uso do prêmio pago pelo Fairtrade é a assembleia em que é votado o Plano de Desenvolvimento do Comércio Justo (Pdcj). Esse plano é realizado a cada ano, e deve conter o planejamento da organização com projetos específicos dirigidos para melhoria da qualidade do café produzido, despesas administrativas da organização, capacitação dos produtores, fortalecimento da organização, seguro de safra, projetos de conservação ambiental e benefício social. O Pdcj deve ser executado pela organização mediante a aprovação em assembleia. 
Assim como a confiança e a cooperação, a participação foi evidenciada através das respostas durante as entrevistas e mediante a observação não participante. Os cafeicultores Fairtrade associados à Cooperativa "Dos Costas" se mostraram bastante envolvidos com as decisões relacionadas à organização e ao grupo de cafeicultores. Além da prestação de serviços como armazenamento, comercialização e assistência técnica, a Cooperativa “Dos Costas" atua como um ambiente coletivo, onde os cafeicultores podem contribuir com a gestão da organização e tomar decisões relacionadas ao futuro do grupo.

Evidenciou-se que a confiança gerou a cooperação entre os membros da cooperativa, a abertura de mecanismos participativos e o interesse dos cooperados em participar. A confiança dos cafeicultores nos gestores e nos membros da cooperativa também foi responsável pela potencialização da cooperação e desencadeou componentes participativos. O estudo evidenciou também a ligação direta entre o capital social e a participação dos cooperados por meio de questões coletivas, ou seja, em torno do "bem comum".

Reunindo dados de diversos países produtores de café, Alvarenga \& Arraes (2017) relacionaram algumas críticas ao sistema de cafeicultura Fairtrade, dentre as quais (1) relação quase três vezes maior de café Fairtrade produzido, comparativamente ao café vendido, o que implica em maior poder de barganha das empresas compradoras perante as cooperativas cafeeiras; (2) insegurança das cooperativas quanto ao desempenho; (3) pequeno efeito da certificação sobre a melhoria das condições de vida dos agricultores; (4) sinais de saturação do mercado de café Fairtrade e (5) custo elevado para certificação Fairtrade.

Araújo et al. (2016) relataram conclusões semelhantes quando consideraram os desafios da certificação Fairtrade no Brasil relacionadas com os (1) altos custos de adesão à certificação, empecilho que exclui os agricultores que dispõem de menos recursos; (2) competição entre produtores que operam em maior escala e os de menor escala de produção; (3) redução do número de organizações de produtores Fairtrade certificadas nos últimos anos. Contudo, concluem que o sistema Fairtrade tem alcançado maior nível de organização nos últimos anos, prestando-se como alternativa ao mercado convencional de café. Assim, avaliam a certificação Fairtrade positivamente, uma vez que tem apoiado os cafeicultores que operam em pequena escala no escoamento da produção e obtenção de preços mais elevados.

\section{Considerações finais}

Nossa pesquisa nos permitiu identificar forte influência do Fairtrade sobre o desenvolvimento do capital social na comunidade de cafeicultores Fairtrade associados à Cooperativa "Dos Costas", cujas repercussões incluem o fortalecimento dos laços e a estruturação das relações de confiança, cooperação e participação entre os cooperados.

A análise documental e as entrevistas em profundidade evidenciaram a existência de capital social em etapa anterior ao processo de adesão do grupo de agricultores ao movimento Fairtrade. O histórico associativo dos 49 cafeicultores, que em 2005 constituíram a Associação Comunitária "Dos Costas", revela a existência de confiança, cooperação e participação. Os eventos que se seguiram, a saber: crescimento do grupo, obtenção da certificação Fairtrade, alteração de natureza jurídica de associação, constituição da Cooperativa "Dos Costas" e aumento do número de associados são indicativos dos vínculos de união que vigoram nessa comunidade de agricultores (confiança, cooperação e participação). Em outras palavras, significa dizer que, considerando-se o período analisado, pôde-se constatar que a filosofia Fairtrade e a aplicação de processos de gestão participativa, cuja adoção foi estimulada pelo sistema, contribuíram positivamente para o desenvolvimento do capital social na comunidade, à medida que as já preexistentes relações de confiança, cooperação e participação foram fortalecidas. 
Contudo, as trajetórias das organizações de agricultores não são constantes, e, de modo geral, são marcadas por períodos de crescimento, estagnação e, em muitos casos, de deterioração. É inegável que a força dos vínculos que unem seus membros desempenha influência preponderante nos momentos de decisão e repercutem no destino das associações/ cooperativas. Nesse sentido, parece claro que a tentativa de compreender a dinâmica social que subjaz à organização da Cooperativa "Dos Costas" assenta-se sobre um pequeno trecho de uma longa história, cujo desfecho está hoje sendo construído por seus próprios agentes. Nesse ponto, é necessário ressaltar que, embora a Cooperativa "Dos Costas" represente, atualmente, um caso de sucesso, não traduz a realidade de todas as organizações de agricultores vinculadas ao sistema Fairtrade, conforme pudemos analisar.

As limitações deste estudo devem ser creditadas ao pequeno número de entrevistas realizadas, considerando que se restringiu a três gestores (gestores/cafeicultores) e seis cafeicultores. Entendemos que o cruzamento entre metodologias de base qualitativa e quantitativa, assim como a aplicação de roteiros de entrevistas no formato de surveys, poderá se constituir em estratégia promissora na condução de estudos futuros que tomem por base o mesmo objeto.

\section{Referências Bibliográficas}

Abramovay, R. (1999). O capital social dos territórios: repensando o desenvolvimento rural. In Anais do $4^{\circ}$ Congresso da Sociedade Brasileira de Economia Política. Porto Alegre.

Alencar, E., \& Gomes, M. A. (1998). Metodologia de pesquisa social e diagnóstico participativo. Lavras: Ed. UFLA/FAEPE.

Alvarenga, R. P., \& Arraes, N. A. M. (2017). Certificação Fairtrade na cafeicultura brasileira: análises e perspectivas. Coffee Science, 12(1), 124-147.

Araújo, G. J. F., Magalhães, D. \& Gomes, E. T. A. (2016). Impactos socioambientais da certificação fairtrade nas cooperativas de produtores familiares de café e manga no Brasil. Confins, 29. https://doi.org/10.4000/confins.11401.

Ávila, V. F. (2006). Cultura de sub/ desenvolvimento e desenvolvimento local. Sobral: Ed. UVA.

Baquero, M. (2000). A vulnerabilidade dos partidos políticos e a crise da democracia na América Latina. Porto Alegre: Universitária/UFRGS.

Bordenave, J. E. D. (1992). O que é participação. 7. ed. São Paulo: Brasiliense.

Buarque, S. C. (1999). Metodologia de planejamento do desenvolvimento local e municipal sustentável: material para orientação técnica e treinamento de multiplicadores e técnicos em planejamento local e municipal. Brasília: IICA.

Carvalho, M. R. O. (2014). Redes Sociais: convergências e paradoxos na ação estratégica. Diálogos Possíveis, 3(1),185-198.

Coordenadora Latino-americana e do Caribe de Pequenos Produtores e Trabalhadores do Comércio Justo - CLAC. (2016). Cálculo de preços comércio justo (Série Mercado Comércio Justo). In J. C. Mattos \& C. Jaramillo (Orgs.), Módulo II.

Coleman, J. S. (1990). Foundations of social theory. Cambridge: The Belknap Press of Harvard University Press.

Conselho dos Exportadores de Café do Brasil - CECAFE. (2019). Consumo. Recuperado em 9 de janeiro de 2019, de www.cecafe.com.br/sobre-o-cafe/consumo/

Cooperativa dos Produtores de Café Especial de Boa Esperança. (2018a). Caderno de campo. Boa Esperança, MG. 
Cooperativa dos Produtores de Café Especial de Boa Esperança. (2018b). Prestação de contas 2017. Boa Esperança, MG.

Coordenadora Latino-americana e do Caribe de Pequenos Produtores e Trabalhadores do Comércio Justo - CLAC. (2018). Comércio justo. Recuperado em 9 de janeiro de 2019, de http://claccomerciojusto.org/pt-br/

Dallabrida, V. R. (2006). A dimensão intangível do desenvolvimento: algumas reflexões preliminares. In M. Baquero \& D. Cremonese (Orgs.), Capital social: teoria e prática. Unijuí: Universidade Regional do Noroeste do Estado do Rio Grande do Sul.

Dallabrida, V. R. (2010). Desenvolvimento Regional: por que umas regiões se desenvolvem e outras não? Santa Cruz do Sul: EDUNISC.

Durston, J. (2003). ¿Qué es capital social comunitario? Políticas Sociales, 38, 1-45.

Demo, P. (2008). Pesquisa social. Serviço Social \& Realidade, 17(1), 11-36.

Fairtrade International - FLO. (2014). Documento explicativo para o critério do comércio justo Fairtrade para organizações de pequenos produtores. Recuperado em 5 de janeiro de 2019, de http://www.fairtrade.net/our_standards.html>

Fairtrade International - FLO. (2018). The Fairtrade system. Recuperado em 3 de abril de 2018, de https://www.fairtrade.net/about-fairtrade/fairtrade-system.html

Flick, U. (2009). Introdução à pesquisa qualitativa (3. ed.). Porto Alegre: The Art of Medication.

Flocert. (2018). Lista pública de critérios de conformidade: organizações de pequenos produtores. Flocert.

Fukuyama, F. (1996). Confiança: as virtudes sociais e a criação da prosperidade. Rio de Janeiro: Rocco.

Gil, A. C. (2008). Métodos e técnicas de pesquisa social (6. ed.). São Paulo: Atlas.

Goulart, M. S. B. (2006). A construção da mudança nas instituições sociais: a reforma psiquiátrica. Pesquisas e Práticas Psicossociais, 1(1), 1-19.

Granovetter, M. (1973). The strength of weak ties. American Journal of Sociology, 78(6), 1360-1380.

Jara, C. J. (2001). As dimensões intangíveis do desenvolvimento sustentável. Brasília: Instituto Interamericano de Cooperação para a Agricultura (IICA).

Laforga, G. (2005). Economia solidária, agricultura familiar e comércio Justo: alinhando convergências, apresentando desafios. In Anais do XXIX Encontro Anual da ANPOCS.

Marteleto, R. M., \& Silva, A. B. O. (2004). Redes e capital social: o enfoque da informação para o desenvolvimento local. Ciência da Informação, 33(3), 41-49.

Martins, S. H. H. T. (2004). Metodologia qualitativa de pesquisa. Educação e Pesquisa, 30(2), 287-298.

Mascarenhas, G. C. S. (2007). O movimento do comércio justo e solidário no Brasil: entre a solidariedade e o mercado Tese de doutorado). Universidade Federal Rural do Rio de Janeiro, Seropédica.

Monastério, L. M. (2006). A retórica do capital social: uma análise da obra de Robert Putnam. In M. Baquero \& D. Cremonese (Orgs.), Capital social: teoria e prática. Unijuí: Universidade Regional do Noroeste do Estado do Rio Grande do Sul.

Neves, D. P. (2003). O associativismo e a imposição do agricultor solidário. In XI Congresso de Sociologia: GT 11: Mundo Rural na Sociedade Brasileira. SBS.

Oliveira, F. (2001). Aproximações ao enigma: o que quer dizer desenvolvimento local? Programa Gestão Pública e Cidadania/EAESP/FGV. São Paulo: Pólis.

Olson, M. (1999). A lógica da ação coletiva (F. Fernandez, Trad.). São Paulo: Edusp. 
Pedini, S. (2011). Fair Trade: alternativa ao mercado convencional de café e processos de empoderamento de cafeicultores familiares (Tese de doutorado). Universidade Federal de Lavras, Lavras.

Putnam, R. D. (1997). Comunidade e democracia: a experiência da Itália moderna. Rio de Janeiro: Fundação Getúlio Vargas.

Romaniello, M. M. (2009). Capital social e accountability em organizações cafeeiras no sul do estado de Minas Gerais (Tese de doutorado). Universidade Federal de Lavras, Lavras.

Sabourin, E. (2011). Sociedades e organizações camponesas: uma leitura através da reciprocidade. Porto Alegre: Editora da UFRGS.

Serafim, M. C., Ronconi, L. F. A., Debetir, E., Jara, E. J., Reis, P. C. G., \& Severino, A. J. (2007). Metodologia do trabalho científico(A. J. Severino, Trad., 23. ed. rev. e atual.). São Paulo: Cortez.

Silva, O. A. C. \& Cândido, G. A. (2009). A influência do capital social em projetos de desenvolvimento local: um estudo exploratório em duas comunidades rurais no município de Bananeiras PB. Qualit@s Revista Eletrônica, 8(1).

Tabosa, F. J. S., Silva, D. M. F., Madalozzo, C. L., \& Mayorga, M. I. O. (2004). A importância do capital social e da solidariedade para o desenvolvimento local: um estudo de caso. In Anais do $42^{\circ}$ Congresso da Sociedade Brasileira de Economia, Administração e Sociologia Rural (Sober) (Vol. 1). Brasília: SOBER.

Vale, G. M. V., Amâncio, R., \& Lauria, M. C. P. (2006). Capital social e suas implicações para o estudo das organizações. Organizações \& Sociedade, 13(36), 45-63. 